\begin{tabular}{|c|c|c|c|c|c|c|}
\hline \multirow{4}{*}{ [mpact Factor: } & ISRA (India) & 3.117 & SIS (USA) & $=0.912$ & ICV (Poland) & $=6.630$ \\
\hline & ISI (Dubai, UAE & $=0.829$ & РИНЦ (Russia) & $=0.156$ & PIF (India) & 1.940 \\
\hline & GIF (Australia) & $=0.564$ & ESJI (KZ) & $=5.015$ & IBI (India) & $=4.260$ \\
\hline & JIF & $=1.500$ & S.JF (Mor & $=5.667$ & OAJI (USA) & $=0.350$ \\
\hline
\end{tabular}

\begin{tabular}{|c|c|}
\hline \multicolumn{2}{|c|}{$\begin{array}{l}\text { SOI: } \underline{1.1 / \mathrm{TAS}} \text { DOI: } \underline{10.15863 / \mathrm{TAS}} \\
\text { International Scientific Journal } \\
\text { Theoretical \& A nnlied Science }\end{array}$} \\
\hline p-ISSN: 2308-4944 (print) & e-ISSN: $2409-0085$ (online) \\
\hline Year: 2019 & Volume: 69 \\
\hline Published: 24.01.2019 & tttp://T-Science.org \\
\hline
\end{tabular}

SECTION 19. Management. Marketing. Public administration.

UDC 677.(575.1):338.58.009.12
QR - Issue

QR - Article

\title{
IMPROVING THE METHODOLOGY FOR ASSESSING THE COMPETITIVENESS OF LIGHT INDUSTRY ENTERPRISES
}

\footnotetext{
Abstract: The article considered the main factors for assessing the competitiveness of light industry enterprises as a marketing complex, quality indicators and financial indicators.

In the activities of marketing complex determined the coefficients of market share, pre-sale preparation, changes in sales, price levels, bringing the product to the consumer, advertising, personal sales, public relations, financial indicators, the ratio of own funds and analyzed the quality indicators.

Key words: competitiveness, price, marketing complex, market share, sales, financial performance, assessment of competitiveness, product quality, the ratio of own funds.

Language: Russian

Citation: Toshpulatov, I. A. (2019). Improving the methodology for assessing the competitiveness of light industry enterprises. ISJ Theoretical \& Applied Science, 01 (69), 215-222.

Soi: http://s-o-i.org/1.1/TAS-01-69-28 Doi: crossef https://dx.doi.org/10.15863/TAS.2019.01.69.28

\section{СОВЕРШЕНСТВОВАНИЯ МЕТОДОЛОГИИ ОЦЕНКИ КОНКУРЕНТОСПОСОБНОСТИ ПРЕДПРИЯТИЙ ЛЕГКОЙ ПРОМЫШЛЕННОСТИ}

Аннотация: В статье рассмотрены основные факторы оценки конкурентоспособности предприятий легкой промышленности как маркетинговый комплекс, показатели качества и финансовые показатели.

В деятельности маркетингового комплекса определены коэффициенты рыночной доли, предпродажной подготовки, изменения объема продаж, уровня иеен, доведения продукта до потребителя, рекламной деятельности, использования персональных продаж, использования связей с общественностью, в финансовых показателях коэффициент обеспеченности собственными средствами и анализированы показатели качества.

Ключевые слова: конкурентоспособность, цена, маркетинговый комплекс, доля рынка, объем продаж, финансовые показатели, оценка конкурентоспособности, качество продукции, коэффициент обеспеченности собственными средствами.
}

\section{Введение}

Легкая промышленность является одним из секторов, способствующих развитию экономику Республики Узбекистана. Принимая во внимание широкий спектр возможностей для дальнейшего развития промышленного сектора, повышение эффективности сети, производство конкурентоспособной продукции соответствующей международным рынкам, и продвижение промышленного бренда на весь мир - является одним из актуальных проблем.
Президент Республики Узбекистан Ш.Мирзиёев подписал Постановление «О Программе мер по дальнейшему развитию текстильной и швейно-трикотажной промышленности на 2017-2019 годы» связано с "Предоставляющее маркетинговые, информационные и консультационные услуги предприятиям легкой промышленности, в том числе вопросы маркетинговых, информационных и консультационных услуг субъектам малого бизнеса и частного предпринимательства, 


\begin{tabular}{|c|c|c|c|c|c|c|}
\hline \multirow{4}{*}{ Impact Factor: } & ISRA (India) & $=3.117$ & SIS (USA) & $=0.912$ & ICV (Poland) & $=6.630$ \\
\hline & ISI (Dubai, UAE & $=0.829$ & РИНЦ (Russia) & $=0.156$ & PIF (India) & $=1.940$ \\
\hline & GIF (Australia) & $=0.564$ & ESJI (KZ) & $=\mathbf{5 . 0 1 5}$ & IBI (India) & $=4.260$ \\
\hline & JIF & $=1.500$ & SJIF (Morocco) & $=5.667$ & OAJI (USA) & $=0.350$ \\
\hline
\end{tabular}

проведение рекламных кампаний на выставках и в публикациях в прессе, продвижение продукции легкой промышленности на экспорт путем широкого охвата экспортного потенциала» которые являются основные направления деятельности предприятй легкой промышленности [1].

Bсе меры, направленные на развитие легкой промышленности, служат повышению экономической эффективности предприятий и выпуску конкурентоспособной продукции. Основными темами статьи являются вопросы определения уровня конкурентоспособности предприятий легкой промышленности, изучения степени конкурентоспособности предприятий, правильной оценки предприятий, выявления недостатков и проблем, а также эффективного использования опыта развитых стран.

\section{Анализ тематических литератур}

Наряду с теоретическим исследованием конкуренции и конкурентоспособности в экономической литературе было разработано много подходов к оценке конкурентоспособности. Чтобы оценить конкурентоспособность продукции, была разработана очень простая в использовании методика оценки конкурентоспособности одних и тех же товаров и услуг. Несмотря на то, что некоторые научные исследования были проведены для оценки конкурентоспособности предприятий, ученые-экономисты не смогли разработать методологию комплексной оценки конкурентоспособности предприятий.

Конкурентоспособность предприятия является неотъемлемой частью любого хозяйствующего субъекта. В частности, для оценки конкурентоспособности предприятия предпринимаются следующие меры:

- разработка мер по повышению конкурентоспособности;

- подбор партнеров для совместной деятельности;

- создание доступа предприятий к новым рынкам;

- инвестиционная деятельность;

- государственное управление экономикой.

В любом случае оценка конкурентоспособности компании направлена на определение месторасположения предприятия на рынке. Основной задачей каждого экономиста, изучающего проблемы конкурентоспособности предприятий, является выявление конкурентоспособности, ее источников и факторов. Различные подходы и подходы метода оценки были разработаны исхода из особенностей конкурентоспособности предприятий легкой промышленности. Ученые из зарубежных стран провели многочисленные исследования по методам оценки конкурентоспособности. Воронов Д.С. изучал методы оценки распределяя на конкурентоспособность производств, конкурентоспособность продукции, матричная, операционная, оценка бизнеса и комбинационные методы [2, с. 92-102].

Проведены многочисленные исследования при выборе и совершенствовании наиболее эффективных методологий диагностики предприятия. Томпсон А.А. и Стрикленд А.Дж. оценили качество и характеристики продукта, его имидж, производственные мощности, технологии, отношения с дилерами, инновационная деятельность, финансовые ресурсы, оценка расходов конкурента и обслуживание клиентов [3, с. 412]. Максимова И.В. при оценке конкурентоспособности предприятия учитывала эффективность управления производственным процессом, эффективность оборотных средств предприятия, реализации товаров, эффективности маркетинговых услуг и конкурентоспособности товара [4, с. 33-39].

Бекмуродова Г. исследователь нашей страны проводила исследования по оценке конкурентоспособности банка на основе системы $\mathrm{BSC}$ по двум покозателям 1) показатели описывающие внешние возможности роста конкурентоспособности и 2) показатели, используемые во внутренних возможностях банка [5, с. 49]. Болтабоев М.Р. использовал маркетинговую стратегию, основанную на теории эффективной конкуренции, для оценки конкурентоспособности текстильной промышленности, на основе которой четырьмя критериями или критериями конкурентоспособности, определенным методом пошагового сравнения экспертов, являются эффективность производственной деятельности, эффективность финансового состояния предприятия, эффективность продажи товаров и продвижение на рынок и конкурентоспособность продукции [6, с. 1-2]. Шарипов И.Б. и Хакимов 3.А. определяли конкурентоспособность исходя из операционной эффективности, инновационной активности предприятия и интегральных показателей рынка [7, с. 3]. Акбаров Н.Г. провел исследование предприятий хлопкоочистительной отрасли по уровню конкурентоспособности волокна, доле рынка, использованию внутренних ресурсов на основе метода сравнительного анализа [8. с. 2].

Нами предложена с помощью коэффициента Фехнера, определять показатели конкурентоспособности учитывая всех особенностей легкой промышленности. Первоначально определяем всех факторов, влияющих на конкурентоспособность продукта 


\begin{tabular}{|c|c|c|c|c|c|c|}
\hline \multirow{4}{*}{ Impact Factor: } & ISRA (India) & $=3.117$ & SIS (USA) & $=0.912$ & ICV (Poland) & $=6.630$ \\
\hline & ISI (Dubai, UAE & $=0.829$ & РИНЦ (Russia & $=0.156$ & PIF (India) & $=1.940$ \\
\hline & GIF (Australia) & $=0.564$ & ESJI (KZ) & $=\mathbf{5 . 0 1 5}$ & IBI (India) & $=4.260$ \\
\hline & JIF & $=1.500$ & SJIF (Morocco & $=5.667$ & OAJI (USA) & $=0.350$ \\
\hline
\end{tabular}

взаимосвязанных с объемом продаж методом эксперта. Исследование показало, что объема продаж предприятий имеет самая высокая связь с маркетинговыми и финансовыми показателями, значительно с качеством, а с изменением цен имеет высокий уровень не прямой зависимости. (см. Таблицу 1).

Таблица 1. Коэффициент Фехнера

\begin{tabular}{|c|c|c|c|c|}
\hline Показатели & $\begin{array}{c}\text { Маркетин- } \\
\text { говые } \\
\text { расходы }\end{array}$ & $\begin{array}{c}\text { Финансовые } \\
\text { показатели }\end{array}$ & $\begin{array}{c}\text { Расходы на } \\
\text { контроль качества }\end{array}$ & Изменение цен \\
\hline Коэффицент & 1 & 1 & 0,6 & $-0,8$ \\
\hline Объем продаж & Пчень высокий & Очень высокий & Значитель-ный & Высокий \\
продукции & $\begin{array}{c}\text { уровень } \\
\text { прямой } \\
\text { зависимости }\end{array}$ & $\begin{array}{c}\text { уровень } \\
\text { прямой } \\
\text { зависи-мости }\end{array}$ & $\begin{array}{c}\text { зависи-мости } \\
\text { уровень не } \\
\text { прямой зависи- } \\
\text { мости }\end{array}$ \\
\hline
\end{tabular}

Таким образом, в качестве факторов влияющих на конкурентоспособность предприятия легкой промышленности, принимаются маркетинговая деятельность, финансовые показатели, цена и контроль качества. Это теоретически точная гипотеза, потому что маркетинг непосредственно связан с объемом продаж предприятия, а продажи сильно связаны с финансовыми показателями. Эффективно используя всех научных исследованний по оценке конкурентоспособности предлагаем предприятия легкой промышленности разделить в три большие группы, которые будут оцениваться как комплекс маркетинга, финансовые показатели и показатели качества. Маркетинговый комплекс включает в себя все аспекты, связанные с производством и продажей товаров, что позволяет им оценивать такие факторы, как доля рынка, стратегия конкурента и потребительский спрос. В целом, маркетинговый комплекс выполняет функцию нападающего. Если маркетинговый комплекс охватывает процесс от начала производства до потребителя, а финансовые показатели оценивают рост или деятельность уменьшения активов предприятия как сумму стоимости деятельности маркетингового комплекса. Качество продукта служит для удовлетворения требований потребителей.

\section{Методология исследования}

С помощью оценки конкурентоспособности будет явно диагностировано недостатки или проблемы на предприятие. Исследуется пути решения проблемы, если она недоступна в текущем периоде, включается в стратегические планы. Для того чтобы использовать методологию оценки конкурентоспособности были тщательно изучены и собраны базы данных, деятельности отдела продаж, маркетинга, контроля качества, бухгалтерия, отдел планирования, складское хозяйство и производственные цеха. На основе собранных данных эффективно использовались такие методы экономического анализа как сравнение, системный подход и логический подход.

\section{Анализ и результаты}

Первоначально оцениваем конкурентоспособность предприятия на основе маркетингового комплекса и финансовых показателей с помощью существующих методов в зарубежных странах [9, с 63-71]. Для оценки маркетингового комплекса используются следующие элементы: 1) продукт; 2) цена; 3) доведение продукта до потребителя; 4) продвижение продукта (маркетинговые коммуникации).

I. Показатели по отдельным элементам комплекса маркетинга.

1. По продукту:

Коэффициент рыночной доли (К

$$
\mathrm{K}_{\mathrm{pд}}=\frac{\mathrm{Q}_{\mathrm{i}}}{\sum \mathrm{Q}_{\mathrm{i}}}
$$

где $\mathrm{Q}_{\mathrm{i}}$ - объем продаж продукта предприятия;

$\sum \mathrm{Q}_{\mathrm{i}}$ - общий объем продаж продукта на рынке.

Коэффициент рыночной доли показывает долю, занимаемую предприятия на рынке.

Коэффичиент предпродажной подготовки $\left(K_{\Pi \Pi)}\right)$

$$
K_{\text {пп }}=\frac{3_{\text {пп }}}{3_{\text {по }}}
$$

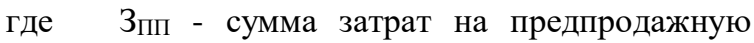
подготовку; 3по - сумма затрат на производство (приобретение) продукта и организацию его продаж.

Этот показатель характеризует усилие предприятия, направленное на рост конкурентоспособности за счет улучшения предпродажной подготовки. В случае, если продукт не требовал предпродажной подготовки в отчетный период, то принимается: $\mathrm{K}_{\text {пп }}=1$. $\left(K_{P}\right)$ :

Коэффициент изменения объема продаж

$$
\mathrm{K}_{\mathrm{p}}=\frac{\mathrm{Q}_{\mathrm{K}}}{\mathrm{Q}_{\mathrm{H}}}
$$




\begin{tabular}{|c|c|c|c|c|c|c|}
\hline \multirow{4}{*}{ Impact Factor: } & ISRA (India) & $=3.117$ & SIS (USA) & $=0.912$ & ICV (Poland) & $=6.630$ \\
\hline & ISI (Dubai, UAE & $=0.829$ & РИНЦ (Russia & $=0.156$ & PIF (India) & $=1.940$ \\
\hline & GIF (Australia) & $=0.564$ & ESJI (KZ) & $=\mathbf{5 . 0 1 5}$ & IBI (India) & $=4.260$ \\
\hline & JIF & $=1.500$ & SJIF (Morocco & $=5.667$ & OAJI (USA) & $=0.350$ \\
\hline
\end{tabular}

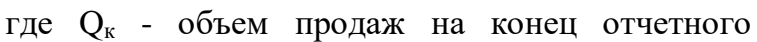
периода; $\mathrm{Q}_{\text {н }}$ объем продаж на начало отчетного периода.

Показывает рост или снижение конкурентоспособности предприятий за счет изменения объема продаж.

2. По цене:

Коэффициент уровня иенн $\left(K_{ц}\right)$ :

$$
\mathrm{K}_{ц}=\frac{\bigsqcup_{\max }+Ц_{\min }}{2 * Ц_{\phi}}
$$

где Ц $Ц_{\min }$ - минимальная цена товара на рынке; Ц ${ }_{\phi}$ цена товара, установленная предприятия.

Коэффициент уровня цен показывает рост или снижение конкурентоспособности предприятия за счет динамики цен на продукт.

3. По доведению продукта до потребителя:

Коэффициент доведения продукта до потребителя $\left(K_{C Б}\right)$ :

$$
\mathrm{K}_{\mathrm{CБ}}=\mathrm{K}_{\mathrm{p}} * \frac{3_{\mathrm{CБ} \mathrm{K}}}{\mathrm{X}_{\mathrm{CБ} \mathrm{H}}}
$$

где $\mathrm{K}_{\mathrm{P}}$ - коэффициент изменения объема продаж; 3 Сь к - сумма затрат на функционирование системы сбыта на конец отчетного периода; ЗСь н - сумма затрат на функционирование системы сбыта на начало отчетного периода.

Показывает стремление предприятия к повышению конкурентоспособности за счет улучшения сбытовой деятельности.

4. По продвижению продукта: $\left(K_{P E K}\right)$ :

Коэффициент рекламной деятельности

$$
\mathrm{K}_{\text {рек }}=\mathrm{K}_{\mathrm{p}} * \frac{\text { РЕЕК К }_{\text {РЕК н }}}{3_{\text {Ре }}}
$$

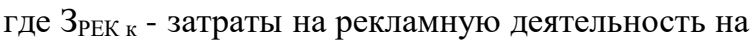
конец отчетного периода;

3Рек н - затраты на рекламную деятельность на начало отчетного периода.

Характеризует стремление предприятия к росту конкурентоспособности за счет улучшения рекламной деятельности.

Коэффициент использования персональных продаж $\left(K_{\text {Перс }}\right)$ :

$$
\mathrm{K}_{\text {Перс }}=\mathrm{K}_{\mathrm{p}} * \frac{3_{\text {ОПл } \mathrm{\kappa}}}{3_{\text {ОПл н }}}
$$

где Зопл к - сумма затрат на оплату труда торговых агентов на конец отчетного периода;
Зопл н - сумма затрат на оплату труда торговых агентов на начало отчетного периода.

Показывает стремление предприятия к росту конкурентоспособности за счет роста персональных продаж с привлечением торговых агентов.

Коэффициент использования связей с общественностью (Ковщ):

$$
\mathrm{K}_{\text {оБщ }}=\mathrm{K}_{\mathrm{p}} * \frac{3_{\text {ОБщ к }}}{3_{\text {оБщ }}}
$$

где 3 общ к - затраты на связи с общественностью на конец отчетного периода;

З общ н - затраты на связи с общественностью на начало отчетного периода.

Показывает стремление предприятий к росту конкурентоспособности за счет улучшения связей с общественностью.

Итоговый

показатель конкурентоспособности маркетинговой деятельности для конкретного продукта можно определить по формуле средней геометрической простой:

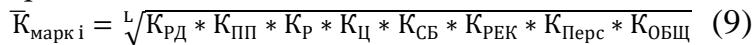

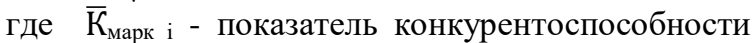
маркетинговой деятельности для конкретного продукта; L - общее число показателей (данном случае $\mathrm{L}=8$ ).

В том случае, если оценка конкурентоспособности маркетинговой деятельности проводится отдельно для различных продуктов, необходимо рассчитать среднее значение показателя конкурентоспособности маркетинговой деятельности для всех продуктов ( $\left.\bar{\kappa}_{\text {марк }}\right)$ по формуле:

$$
\overline{\mathrm{K}}_{\text {марк }}=\frac{\sum_{i=1}^{n} \overline{\mathrm{K}}_{\text {марк } i}}{n}
$$

где n - количество продуктов (услуг) фирмы.

С целью оценки конкурентоспособности предприятия легкой промышленности СП ООО "INDORAMA KOKAND TEXTILE" и СП OOO

\begin{tabular}{|c|c|c|c|}
\hline $\begin{array}{ll}\text { Элемент } & \text { комплекса } \\
\text { маркетинга } & \end{array}$ & Показатель & $\begin{array}{c}\text { СП ООО “Кува- } \\
\text { текстил” }\end{array}$ & $\begin{array}{c}\text { CП OOO } \\
\text { "INDORAMA } \\
\text { KOKAND TEXTILE" }\end{array}$ \\
\hline \multirow[b]{2}{*}{ Продукт } & $\begin{array}{l}\text { Коэффициент рыночной доли } \\
(\text { КРд) }\end{array}$ & 0.3 & 0.7 \\
\hline & $\begin{array}{l}\text { Коэффициент предпродажной } \\
\text { подготовки }\left(К_{\Pi п}\right)\end{array}$ & 0.9 & 0.3 \\
\hline
\end{tabular}
“Қуватекстил” Ферганской области был выбран наиболее продуктивный тип пряжи №30 и в результате анализа данных предприятий были получены следующие результаты (см. таблицу 2).

Таблица 2. Анализ конкурентоспособности маркетинговой деятельности предприятий. 


\begin{tabular}{|c|c|c|c|c|c|c|}
\hline \multirow{4}{*}{ Impact Factor: } & ISRA (India) & $=3.117$ & SIS (USA) & $=0.912$ & ICV (Poland) & $=6.630$ \\
\hline & ISI (Dubai, UAE & $=0.829$ & РИНЦ (Russia & $=0.156$ & PIF (India) & $=1.940$ \\
\hline & GIF (Australia) & $=0.564$ & ESJI (KZ) & $=5.015$ & IBI (India) & $=4.260$ \\
\hline & JIF & $=1.500$ & SJIF (Morocce & $=5.667$ & OAJI (USA) & $=0.350$ \\
\hline
\end{tabular}

\begin{tabular}{|c|c|c|c|}
\hline & $\begin{array}{l}\text { Коэффициент изменения объема } \\
\text { продаж }\left(К_{\mathrm{P}}\right)\end{array}$ & 1.2 & 1.3 \\
\hline Цена & Коэффициент уровня цен $\left(\mathrm{K}_{ц}\right)$ & 1.01 & 1.25 \\
\hline $\begin{array}{l}\text { Доведение продукта до } \\
\text { потребителя }\end{array}$ & $\begin{array}{lr}\text { Коэффициент } & \text { доведения } \\
\text { продукта до потребителя }\left(\mathrm{K}_{\text {СБ }}\right)\end{array}$ & 1.5 & 2.16 \\
\hline \multirow{3}{*}{ Продвижение продукта } & $\begin{array}{ll}\text { Коэффициент } & \text { рекламной } \\
\text { деятельности (КРЕК) }\end{array}$ & 0.9 & 1.95 \\
\hline & $\begin{array}{l}\text { Коэффициент } \quad \text { использования } \\
\text { персональных продаж }\left(К_{\text {Перс })}\right.\end{array}$ & 1.6 & 2.34 \\
\hline & 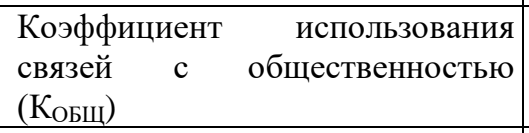 & 1.4 & 0.6 \\
\hline \multicolumn{2}{|c|}{$\begin{array}{l}\text { Показатель конкурентоспособности } \\
\text { маркетинговой деятельности конкретного товара }\left(\bar{\kappa}_{\text {марк і }}\right)\end{array}$} & 0.99 & 1.09 \\
\hline \multicolumn{2}{|c|}{$\begin{array}{lccc}\text { Среднее } & \text { значение } & \text { показателя } & \text { конкурентоспособности } \\
\text { маркетинговой деятельности для всех товаров - }\left(\overline{\mathrm{K}}_{\text {марк }}\right)\end{array}$} & 0.99 & 1.09 \\
\hline
\end{tabular}

Для анализа конкурентоспособности финансового состояния предприятия определятся финансовые показатели.

II. Финансовые показатели оценки конкурентоспособности предприятия. Белоусов В.Л. для оценки конкурентосоьности по финансовым показателям выбрал коэффициенты текущей ликвидности и обеспеченность собственных активов. Но, при оценке финансовых показателей компании, обнаружена ошибки. То есть значение коэффициента текущей ликвидности должен быть не менее 2 и не более 3, и мы можем сделать вывод, о том что чем выше коэффициент, тем более конкурентоспособность. Следовательно, использование этого коэффициента приведет к ошибкам в оценке.

Для оценки финансового состояния компании используем коэффицент обеспеченности собственных активов. Чем болше этот коэффициент 0,1 , тем лучше и соответствует другим оценочным показателям.
Коэффициент обеспеченности собственными средствами (Косс) определяется как отношение разности между объемами источников собственных средств (итог 3-го раздела баланса) и фактической стоимостью основных средств и прочих вне оборотных активов (итог 1-го раздела баланса) к фактической стоимости находящихся в наличии у фирмы оборотных средств в виде производственных запасов, незавершенного производства, готовой продукции, денежных средств, дебиторской задолженности и прочих оборотных активов (итог 2-го раздела баланса).

$$
\mathrm{K}_{\text {OCС }}=\frac{\mathrm{CK}-\mathrm{B}_{\text {необ }} \mathrm{A}}{\text { ОА }}
$$

Нормативное значение - не менее 0,1 (чем больше, тем лучше). Характеризует наличие у организации собственных оборотных средств, необходимых для ее текущей деятельности.

На основании данных баланса СП ООО "INDORAMA KOKAND TEXTILE" и СП OOO “Қуватекстил" выполнили следующие расчеты (см. Таблицу 3).

Таблица 3. Анализ финансовых показателей оценки конкурентоспособности предприятия (2017 год, тыс. сум)

\begin{tabular}{|l|c|c|c|c|}
\hline \multicolumn{2}{|c|}{ Показатель } & \multicolumn{2}{|c|}{ СП ООО “Куватекстил” } & \multicolumn{2}{c|}{$\begin{array}{c}\text { СП ООО “INDORAMА КОКАND } \\
\text { ТЕХTILE” }\end{array}$} \\
\cline { 2 - 5 } & $\begin{array}{c}\text { На начало } \\
\text { период }\end{array}$ & $\begin{array}{c}\text { На конец } \\
\text { период }\end{array}$ & $\begin{array}{c}\text { На начало } \\
\text { Период }\end{array}$ & $\begin{array}{c}\text { На конец } \\
\text { период }\end{array}$ \\
\hline Оборотные активы (ОА) & 62623841 & 60353934 & 626326350 & 720678400 \\
\hline Собственный капитал (СК) & 54605982 & 55876645 & 535693600 & 633961250 \\
\hline $\begin{array}{l}\text { Вне оборотные активы } \\
\text { (ВнеобА) }\end{array}$ & 29457048 & 29111500 & 178683050 & 241396350 \\
\hline
\end{tabular}




\begin{tabular}{|c|c|c|c|c|c|c|}
\hline \multirow{4}{*}{ Impact Factor: } & ISRA (India) & $=3.117$ & SIS (USA) & $=0.912$ & ICV (Poland) & $=6.630$ \\
\hline & ISI (Dubai, UAE & $=0.829$ & РИНЦ (Russia) & $=0.156$ & PIF (India) & $=1.940$ \\
\hline & GIF (Australia) & $=0.564$ & ESJI (KZ) & $=\mathbf{5 . 0 1 5}$ & IBI (India) & $=4.260$ \\
\hline & JIF & $=1.500$ & SJIF (Morocco) & $=5.667$ & OAJI (USA) & $=0.350$ \\
\hline
\end{tabular}

\begin{tabular}{|l|l|l|l|l|}
\hline $\begin{array}{l}\text { Коэффициент } \\
\text { обеспеченности } \\
\text { собственными средствами } \\
\text { (Косс) }\end{array}$ & 0,40 & 0,44 & 0,57 & 0,54 \\
\hline
\end{tabular}

III.Показатели качества оценки конкурентоспособности предприятий. Чтобы оценить конкурентоспособность продукции с помощью качественных показателей, нам нужны показатели какого-либо вида продукции. Как мы уже упоминали, исследование проводится с использованием оборудования Uster, отбирая образцы пряжи типа № 30 СП ОOО "INDORAMA KOKAND TEXTILE” и CП OOO "Қуватекстил". По результатам проверки собираем данные основных показателей, таких как тонкость (Thin), толшина (Thick), неровномерность (Neps) и устойчивость (Rnt). Если результаты соответствуют требованиям ГОСТ, оцениваем коэффициентом 1 , если не соответствуют равен 0 . Основной причиной оценки коэффицентом является согласованность с приведенными выше маркетинговыми и финансовыми показателями. Если качество пряжи ниже, чем стандартной, указывает на более высокое качество продукта, а высокое на низкое качество продукта. Поэтому мы используем два коэффициента 0 и 1 . В общем если показатели, качество продукции является высоким, когда показатели качества предприятия равны 4 коэффициент по сравнению сопоставляемого предприятия равняетса 4 , то качества продукции будеет высоким (см. Таблицу 4).

Таблица 4. Показатели качества пряжи типа № 30.

\begin{tabular}{|l|c|c|c|c|c|c|}
\hline Показатель & $\begin{array}{c}\text { Единица } \\
\text { измерения }\end{array}$ & $\begin{array}{c}\text { По стан- } \\
\text { дарту }\end{array}$ & $\begin{array}{c}\text { OOO } \\
\text { "INDORAMA } \\
\text { KOKAND } \\
\text { TEXTILE" }\end{array}$ & $\begin{array}{c}\text { Соот-ветст- } \\
\text { вие стан-дарту }\end{array}$ & $\begin{array}{c}\text { СП ООО } \\
\text { "Кува- } \\
\text { текстил" }\end{array}$ & $\begin{array}{c}\text { Соответ- } \\
\text { ствие стан- } \\
\text { дарту }\end{array}$ \\
\hline Тонкость & Thin, штук & 0 & 0 & 1 & 1 & 0 \\
\hline Толшина & Thick, штук & 10 & 13 & 0 & 59 & 0 \\
\hline Неровномерность & Neps, штук & 16 & 13 & 1 & 211 & 0 \\
\hline Устойчивость & $\begin{array}{c}\text { Rnt, санти } \\
\text { Ньютон }\end{array}$ & 13 & 13 & 1 & 15,12 & 0 \\
\hline
\end{tabular}

Общий результат OOO "INDORAMA KOKAND TEXTILE”- 3, CП ООО "Қуватекстил" - 0, т.е. выявлено, что высокое качество имеет продукции, производимой OOO "INDORAMA KOKAND TEXTILE”. Во время стажировки определялась, что существует разница между качеством продукции предприятия. Это объясняется тем, что на преприятии ООО "INDORAMA KOKAND TEXTILE" имеется повторно чесалноя техника. Поскольку эта техника недоступна в СП ООО “Қуватекстил", имеется в нити и пряже много nерs.

Таким образом, полная формула расчета конкурентоспособности предприятия (КР) выглядит следующим образом:

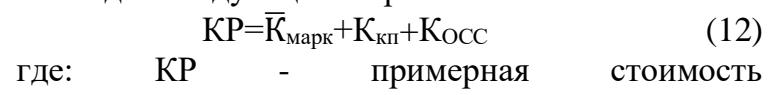
конкурентоспособности предприятия;
$\overline{\mathrm{K}}_{\text {марк }} \quad$ - $\quad$ среднее значение конкурентоспособности маркетинговой деятельности для товаров;

Ккп - показатель качества продукции;

КОсС - коэффициент обеспеченности собственными средствами

Нами предложена методика сложения коэффициентов, потому что если коэффициент умножается то, показатель равняется нулю и в итоге, общий показатель предприятия исчезнет. Поэтому использование метода сложения коэффициент считается эффективным.

Чем выше значение коэффицента конкурентоспособности, тем выше конкурентоспособность предприятия.

СП ООО “Қуватекстил” $\mathrm{KP}=0.99+0+0,44=1,43$

OOO "INDORAMA KOKAND TEXTILE" $\mathrm{KP}=1.09+3+0,54=4,63$ 


\begin{tabular}{|c|c|c|c|c|c|c|}
\hline \multirow{4}{*}{ Impact Factor: } & ISRA (India) & $=3.117$ & SIS (USA) & $=0.912$ & ICV (Poland) & $=6.630$ \\
\hline & ISI (Dubai, UAE & $=0.829$ & РИНЦ (Russia) & $=0.156$ & PIF (India) & $=1.940$ \\
\hline & GIF (Australia) & $=0.564$ & ESJI (KZ) & $=5.015$ & IBI (India) & $=4.260$ \\
\hline & JIF & $=1.500$ & SJIF (Morocco) & $=5.667$ & OAJI (USA) & $=0.350$ \\
\hline
\end{tabular}

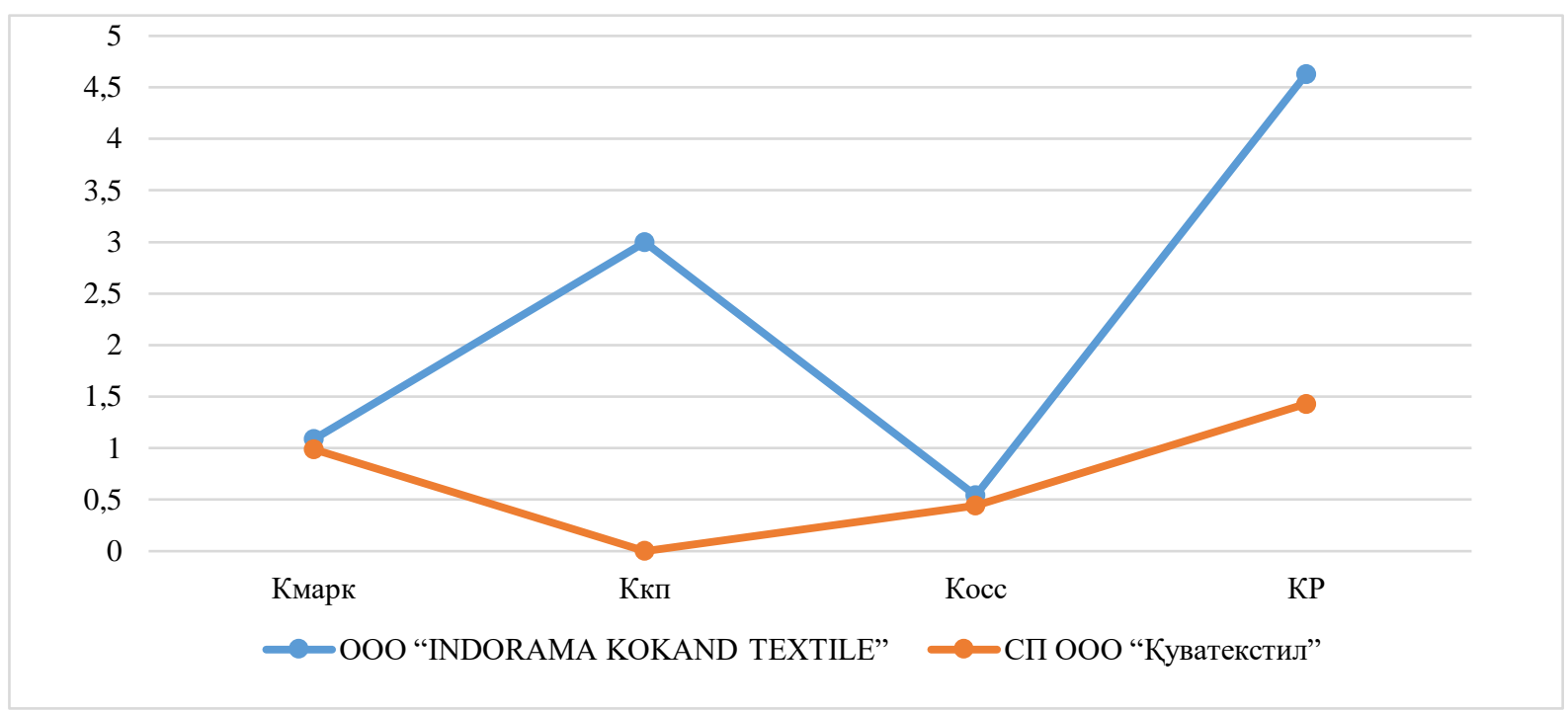

Рисунок 1. Показатели конкурентоспособности предприятия

\section{Выводы и предложения}

В методике было проведено сравнение двух или более лет деятельности предприятия, чтобы дать более точную оценку предприятиям на основе характеристик маркетингового комплекса, исследовали деятельность двух конкурентоспособных предприятий в Ферганской области в виде сравнения в таблицах 2 и 3. Результаты исследования показали, что СП ООО «Куватекстиль» имеет низкую степень конкурентоспособности это связано с низкими показателями коэффицентов рыночной доли, объмом продаж, рекламной деятельностью, качеством продукции и обеспечением собственных активов.

В целях повышения конкурентоспособности предприятия рекомендуем проводить следующие мероприятия:

- развитие навыков маркетинговых услуг специалистов-экспортеров с учетом на направленности большинства продуктов предприятия экспорт;

$$
\text { - с у учетом }
$$

совершенствования рекламной создать базу данных как возможности деятельности, эффективное использование сайтов социальных сетей, реклама на веб-сайтах интернета, описания рекламы производимых продуктов, характеристика продукта, уровни качества производства продукции на основе, стандарта ISO, а также открытие страниц в социальных сетях, таких как самых популярных telegram, Facebook;

- разработка стратегических планов каждого отдела и цеха по развитию предприятия;

- пересмотреть состав должностных инструкций работников для обеспечения конкурентоспособности и введения требований по улучшению степени качества продукции;

- повышение ответственности персонала за предотвращения негативных последствий для имиджа предприятия, таких как использование хлопко сорта при производстве продукта, использование остатков, смешивание других видов хлопка;

- для эффективного использования преимуществ, предоставляемых этому сектору, необходимо импортировать текстильное оборудование из Турции, Кореи и других стран.

\section{Conclusion}

\section{References:}




\begin{tabular}{|c|c|c|c|c|c|c|}
\hline \multirow{4}{*}{ Impact Factor: } & ISRA (India) & $=3.117$ & SIS (USA) & $=0.912$ & ICV (Poland) & $=6.630$ \\
\hline & ISI (Dubai, UAE & $=0.829$ & РИНЦ (Russia) & $=0.156$ & PIF (India) & $=1.940$ \\
\hline & GIF (Australia) & $=0.564$ & ESJI (KZ) & $=5.015$ & IBI (India) & $=4.260$ \\
\hline & JIF & $=1.500$ & SJIF (Morocco) & $=5.667$ & OAJI (USA) & $=0.350$ \\
\hline
\end{tabular}

1. (n.d.). O’zbekiston Respublikasi Prezidenti Sh.Mirziyoyevning 2016 yil 21 dekabrdagi “2017-2019 yillarda to'qimachilik va tikuvtrikotaj sanoatini yanada rivojlantirish choratadbirlari dasturi to'g'risida"gi PQ-2687-sonli qarori.

2. Voronov, D. S. (2014). Dinamicheskiy podxod k otsenke konkurentosposobnosti predpriyatiy. Marketing v Rossii i za rubejom, №5, 92-102.

3. Tompson, A. A., \& Striklend, A. D. (2000). Strategicheskiy menedjment: kontseptsii $i$ situatsii. Uchebnik dlya vuzov. (p.412). M.:INFRA-M.

4. Maksimova, I. V. (1996). Otsenka konkurentosposobnosti promishlennogo predpriyatiya. Marketing, №3, 33-39.

5. Bekmurodova, G. A. (2017). Tijorat banklari raqobatbardoshligini oshirishning innovatsion marketing kontseptsiyasini takomillashtirish. Dissertatsiya. (p.49). T: TDIU.

6. Boltabayev, M. R. (2011). “To'qimachilik sanoati korxonalarining raqobatdoshligini baholash uslubini takomillashtirish". T:, "Iqtisodiyot va innovatsion texnologiyalar" ilmiy elektron jurnali, №1, 1-2.

7. Sharipov, I. B., \& Xakimov, Z. A. (2017). Yengil sanoat korxonalari raqobatbardoshligini baholash uslublarini takomillashtirish. - T:, "Iqtisodiyot va innovatsion texnologiyalar" ilmiy elektron jurnali, №3, 3.

8. Akbarov, N. G. (2017). Paxta tozalash korxonalari raqobatbardoshligini baholash "Iqtisodiyot va innovatsion texnologiyalar" ilmiy elektron jurnali, №1, 2 .
9. Belousov, V. L. (2001). Analiz konkurentosposobnosti firm. Marketing $v$ Rossii i za rubejom, №5, 63-71.

10. Ashurov, M. S., \& Toshpulatov, I. A. (2014). Nekotorie voprosi formirovaniya podsistemi risk-menedjmenta $\quad \mathrm{v}$ sisteme upravleniya promishlennimi predpriyatiyami. Jurnal nauchnix publikatsiy aspirantov $i$ doktorantov, №. 3, 32-34.

11. Margianti, E. S., et al. (2014). Systematical analysis of the position and further development of Uzbekistan national industry in the case of economic modernization. Monograph. Indonesia, Jakarta. Indonesia, Jakarta, Gunadarma Publisher.

12. Kurpayanidi, K. I. (2015). Predprinimatelstvo $v$ sovremennoy institutsionalnoy srede. Monografiya. Palmarium Publishing. Saarbrucken. Germany.

13. Kurpayanidi, K. I., \& Urmonov, A. A. (2016). Sovremennie tendentsii dalneyshego razvitiya Shanxayskoy organizatsii sotrudnichestva (SHOS) v usloviyax globalizatsii. Molodoy ucheniy, №. 17, 433-435.

14. Ashurov, M. S. (2013). Problemi riskmenedjmenta na promishlennix predpriyatiyax $\mathrm{v}$ usloviyax transformatsii ekonomiki. Aktualnie problemi gumanitarnix $i$ sotsialnoekonomicheskix nauk, №. 7-3. 6-8. 